\title{
Effects of surgery under sevoflurane anesthesia with different concentrations on the acquisition of spatial memory in adult rats
}

\author{
Natsuko Yamamoto, Takashi Horiguchi, Toshiaki Nishikawa \\ Department of Anesthesia and Intensive Care Medicine, \\ Akita University Graduate School of Medicine, Akita, Japan
}

\section{Background and Goal of Study}

- There is an ongoing debate whether the depth of anesthesia correlates to the incidence of postoperative cognitive impairments in elderly patients. ${ }^{1)}$

- We investigated the effects of surgery under anesthesia with different concentrations of sevoflurane on the acquisition of spatial memory in adult rats to obtain fundamental data for our future experiments using aged rats.

\section{Materials and Methods}

- Animals: male SD rats (7-9M, 610-750g), n=15

- Groups: Light anesthesia (LA) group $(n=5)$, Deep anesthesia (DA) group $(n=5)$, Control (C) group $(n=5)$

- Rats in the LA and DA groups received $2 \%$ and $4 \%$ inspired concentration of sevoflurane, respectively, plus 33\% oxygen in nitrogen for 2 hours, being spontaneously breathing.

- A catheter was inserted into the tail artery to monitor blood pressure and take blood samples in LA and DA groups. Norepinephrine was infused continuously in the DA group.

- C group didn't received both anesthesia and surgery, were put into the chamber with 33\% oxygen in nitrogen for 2 hours.

- LA and DA groups underwent fracture of the left femur and pinning surgery.

- Spatial learning was assessed on the $1,2,3,6$ and $7^{\text {th }}$ day after the experiment by using Morris Water Maze test, recording the time taken to reach the platform and the total swimming distance.

- Parametric data were expressed as mean \pm SD using Student's $t$ test, time and distance as (median[min-max]), using MannWhitney U test, Kruscal-Wallis test and Dunn's multiple comparison, with $p<0.05$ being statistically significant.

\section{Results and Discussion}

- Mean atrial blood pressure(mBP) were significantly lower in DA group than those in LA group. (Table1.)

- There were no significant differences among the three groups in the time taken to reach the platform from the $1^{\text {st }}$ to $6^{\text {th }}$ day. (Figure 1.)

- On the $7^{\text {th }}$ day, the time spent in LA group (57[51-89]) was significantly longer than those in DA group (39[6-46]) and C group (14[5-27]). (Figure 1.)

- The swimming distance was significantly shorter in DA than C group on the $2^{\text {nd }}$ day, and longer in LA group than $C$ group on the $7^{\text {th }}$ day. (Figure 2.)

- It has been reported that the effects of volatile anesthetics are different in various parts in the brain ${ }^{2)}$. So there seems to be unbalanced state of demand and supply of oxygen due to the spotted metabolic suppression of brain, and it may be caused to delayed brain dysfunction.
Table 1. Parametric data of pre and post surgery

\begin{tabular}{ccccccccc}
\hline pre & $\begin{array}{c}\mathrm{HR} \\
(/ \mathrm{min})\end{array}$ & $\begin{array}{c}\mathrm{mBP} \\
(\mathrm{mmHg})\end{array}$ & $\begin{array}{c}\mathrm{BT} \\
\left({ }^{\circ} \mathrm{C}\right)\end{array}$ & $\mathrm{pH}$ & $\begin{array}{c}\mathrm{PO}_{2} \\
(\mathrm{mmHg})\end{array}$ & $\begin{array}{c}\mathrm{PCO}_{2} \\
(\mathrm{mmHg})\end{array}$ & $\begin{array}{c}\mathrm{Glu} \\
(\mathrm{mg} / \mathrm{dl})\end{array}$ & $\begin{array}{c}\mathrm{Hb} \\
(\mathrm{g} / \mathrm{dl})\end{array}$ \\
\hline LA & 335 & 106 & 37.6 & 7.45 & 181 & 45.8 & 117 & 13.6 \\
& \pm 27.7 & \pm 6.03 & \pm 0.21 & \pm 0.02 & \pm 16.3 & \pm 2.93 & \pm 12.2 & \pm 0.10 \\
DA & 331 & ${ }^{*} 91.6$ & 37.6 & 7.44 & 182 & 46.6 & $* 144$ & 13.9 \\
& \pm 23.2 & \pm 1.02 & \pm 0.37 & \pm 0.03 & \pm 4.02 & \pm 4.22 & \pm 18.5 & \pm 0.37 \\
\hline post & & & & & & & & \\
\hline LA & 305 & 109 & 37.3 & 7.42 & 171 & 48.8 & 102 & 13.7 \\
& \pm 17.8 & \pm 7.84 & \pm 0.07 & \pm 0.02 & \pm 29.5 & \pm 3.97 & \pm 6.31 & \pm 0.52 \\
DA & 290 & $* 90.0$ & 37.4 & 7.39 & 154 & 52.4 & $* 146$ & 13.4 \\
& \pm 20.4 & \pm 3.22 & \pm 0.16 & \pm 0.04 & \pm 15.6 & \pm 8.09 & \pm 11.7 & \pm 0.48 \\
\hline
\end{tabular}

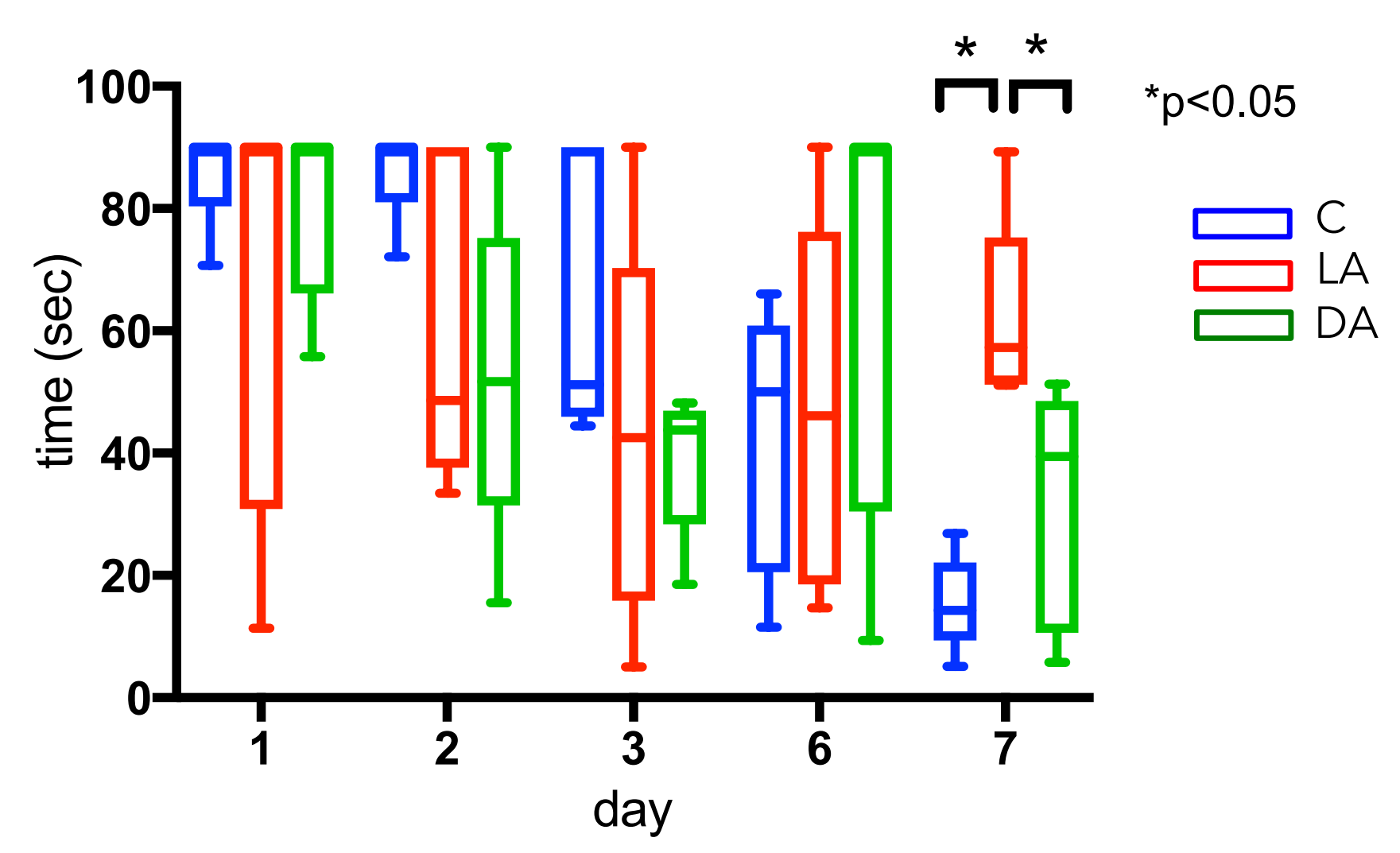

Fig 1. Time taken to reach the platform
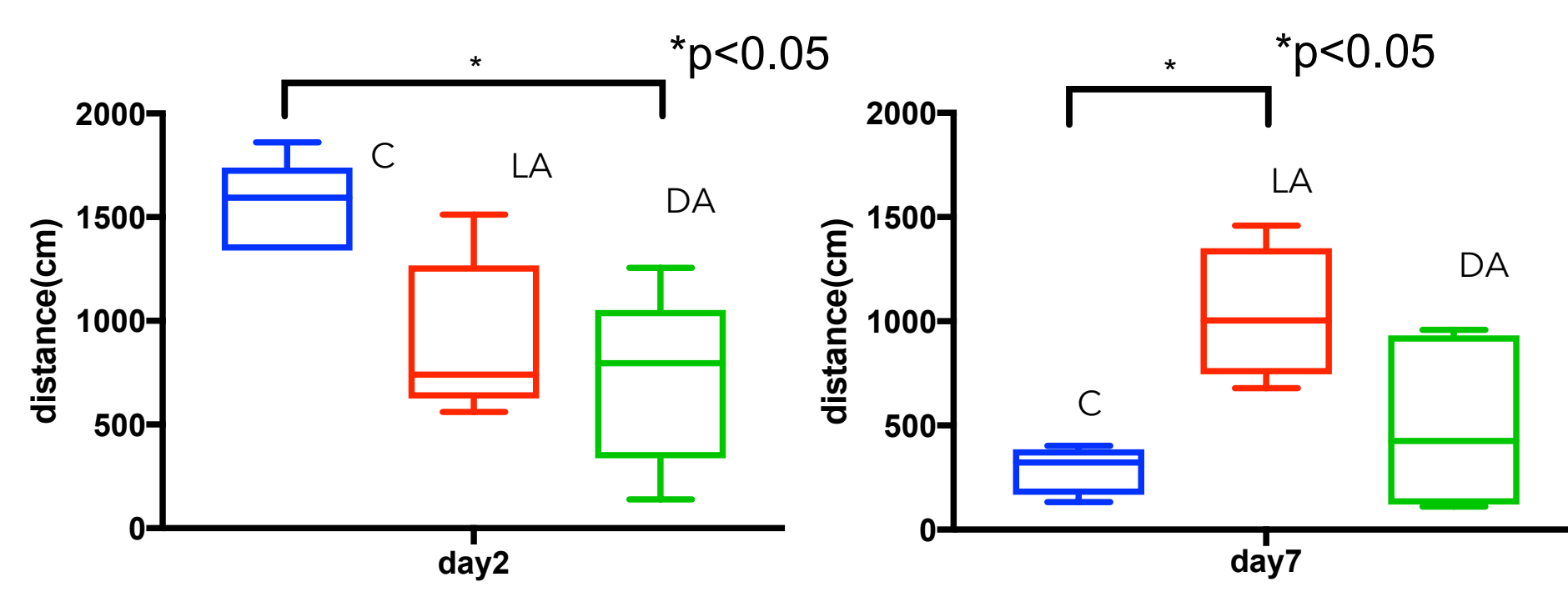

Fig 2. Total swimming distance on the $2^{\text {nd }}$ and $7^{\text {th }}$ day

\section{Conclusion}

- Acquisition of spatial cognitive function was similar among groups until 6 days after anesthesia and surgery, regardless of sevoflurane concentrations.

- On the $7^{\text {th }}$ day, spatial cognitive dysfunction became apparent in the LA group.

- Our findings suggest that surgery under light anesthesia is likely to cause delayed central nervous system dysfunction. 